\title{
Dissociative Symptoms and Amnesia in Dutch Concentration Camp Survivors
}

\author{
Harald Merckelbach, Theo Dekkers, Ineke Wessel, and Anne Roefs
}

\begin{abstract}
We examined to what extent dissociative phenomena in concentration camp survivors are related to posttraumatic stress symptoms. Self-reports of amnesia for traumatic war events and other dissociative experiences were studied in a sample of 31 Dutch survivors of World War II (WWII) Japanese concentration camps. Seventeen survivors treated for war-related psychiatric symptoms were compared to 14 concentration camp survivors who had no psychiatric diagnosis. Although survivors who received treatment scored significantly higher on the Impact of Event Scale and the Post-Traumatic Symptom Scale than control survivors, the two groups did not differ in
\end{abstract}

$\mathbf{P}$ SYCHOGENIC or dissociative amnesia refers to an "inability to recall important personal information, usually of a traumatic or stressful nature, that is too important to be explained by ordinary forgetfulness" (DSM-IV; p. 477). It is often assumed that psychogenic amnesia for traumatic war events is a common phenomenon among WWII veterans ${ }^{1}$ and WWII concentration camp survivors. ${ }^{2}$ However, this assumption heavily rests on anecdotal case reports that are open to alternative interpretations. ${ }^{3}$ Moreover, some studies suggest that only a small minority of war victims report psychogenic amnesia. For example, Kuch and $\mathrm{Cox}^{4}$ studied a sample of 124 Jewish Holocaust survivors and found that with an estimated prevalence rate of $3.2 \%$, psychogenic amnesia was relatively rare in this group. Likewise, at least two studies $^{5,6}$ of Holocaust survivors' autobiographical memories concluded that their failure to recall certain details does not exceed the incidence of normal forgetfulness. This is in line with a recent study $^{7}$ on the psychological effects of political imprisonment in the former German Democratic Republic, showing that only a small minority of severely traumatized survivors reported psychogenic amnesia.

Psychogenic amnesia is generally considered to be a hallmark feature of dissociative symptomatology. ${ }^{8}$ Yehuda et al. ${ }^{9}$ noted that the link between dissociative symptomatology and concentration camp experiences is not a straightforward one. Although in their study, Holocaust survivors with post-traumatic stress disorder (PTSD) reported more dissociative symptoms than either Holocaust survivors without PTSD or a comparison group of terms of accessibility of war memories or dissociative experiences. Levels of post-traumatic stress symptoms were not significantly correlated with dissociative experiences. In both groups, reports of psychogenic amnesia for traumatic events were rare. Our results support previous studies demonstrating that post-traumatic stress symptoms are not necessarily accompanied by dissociative experiences. They also contradict the suggestion that amnesia is a common phenomenon in people who have been exposed to war atrocities.

Copyright 2003, Elsevier Science (USA). All rights reserved.

nontraumatized individuals, it was also the case that survivors with PTSD had dissociation levels that were well below those of other categories of PTSD patients. This led the authors to conclude that PTSD and dissociation are separate constructs.

The current study was a further attempt to elucidate the connection between PTSD symptoms and dissociation in concentration camp survivors. In addition, we were interested in the frequency with which reports of psychogenic amnesia occur in these survivors. Our study involved two groups. One group consisted of Dutch survivors of Japanese concentration camps in Indonesia during World War II (WWII) who currently received treatment for their war-related psychiatric symptoms. The second group consisted of Dutch survivors of Japanese concentration camps who had no psychiatric symptoms. We included this nonsymptomatic control group to test the assumption that psychogenic amnesia is linked to PTSD symptoms and that trauma exposure per se is a necessary, but not sufficient condition for psychogenic amnesia to develop. ${ }^{10}$ Both groups were given measures of PTSD-related distress and dissociative symptom-

From the Department of Experimental Psychology and the Faculty of Law, University of Maastricht, The Netherlands.

Supported by a grant from the Dutch Council for Scientific Research (N.W.O. 575-29-001) awarded to H.M.

Address reprint requests to Harald Merckelbach, Department of Experimental Psychology, University of Maastricht, PO Box 616, 6200 MD, Maastricht, The Netherlands.

Copyright 2003, Elsevier Science (USA). All rights reserved. 0010-440X/03/4401-0012\$35.00/0

doi:10.1053/comp.2003.50011 
atology. Furthermore, they were interviewed about the accessibility of their traumatic memories.

\section{METHOD}

\section{Participants}

From a private practice specialized in the psychiatric treatment of WWII survivors, 17 patients (10 women) were recruited. Only those survivors were included who at the time of their imprisonment were older than 5 years. This was done in order to ensure that infantile amnesia could not account for reports of psychogenic amnesia. Accordingly, mean age of the survivors receiving treatment at the time of the study (end of $1998)$ was 62.2 years $(\mathrm{SD}=3.8)$. On the average, they had been in treatment for 22 months $(\mathrm{SD}=9.6)$. In addition, survivors receiving treatment were only included if they completed the Impact of Event Scale ${ }^{11}$ and the self-report version of the PTSD Symptom Scale ${ }^{12}$ with reference to a traumatic war experience. War experiences that were specified were usually of a horrifying nature involving such events as rape, torture and/or witnessing the execution of a parent. Finally, survivors were included if screening with the Structured Clinical Interview for DSM-IV ${ }^{13}$ confirmed that they suffered from an anxiety, mood, or axis II disorder. Patients with a psychotic illness or an organic brain syndrome were excluded. Of the 17 survivors who were in treatment, 11 were diagnosed with PTSD (of whom two had a comorbid diagnosis of major depressive disorder [MDD]), two suffered from MDD, and four had an anxiety disorder or suffered from dysthymia.

The comparison group consisted of 14 participants (five women) who were recruited through newspaper advertisements in which survivors of WWII Japanese concentration camps without psychiatric complaints were invited to participate in the current study. Their mean age was 62.0 years $(\mathrm{SD}=4.3)$. Control participants were only included if a telephone-administered version of the Structured Clinical Interview for DSM-IV confirmed that they did not suffer from current psychopathology and had no history of PTSD or MDD. All control participants had been imprisoned in one of the Japanese concentration camps and so they roughly had a similar background as the survivors who received treatment. After complete description of the study to all participants, written informed consent was obtained.

\section{Instruments and Procedure}

After survivors had given their informed consent, they were given a number of tests and self-report questionnaires. Among the self-report scales were the Impact of Event Scale, ${ }^{11}$ the self-report version of the PTSD Symptom Scale, ${ }^{12}$ and the Dissociative Experiences Scale. ${ }^{14}$ Cronbach alpha coefficients for these scales were $0.93,0.92$, and 0.91 , respectively. In a separate session that took place 1 week later, survivors were interviewed about the accessibility of their traumatic memories. This structured interview was performed by an experienced clinician and contained the following three open-ended items that are relevant for the phenomenon of psychogenic amnesia: "Do you think that memories of your most aversive war experiences have been stable across your life?" (answers were coded as "yes, "no," or "I don't know"); "Has the accessibility of your war memories changed across your life?" (answers were coded as "no, it has always been the same"; "yes, it has decreased"; "yes, it has increased"; or "I don't know"); and "Has there ever been a period in your life that the war memories were not fully accessible?' (answers were coded as "no, they have always been accessible"; "yes, the memories were there, but I really tried hard not to think of them"; "yes, because memories were completely lost"; or "I don't know"). Interviews were transcribed and then coded by an independent rater who was blind with respect to the purpose of the current study. To establish the reliability of these ratings, a second rater evaluated five randomly selected interview transcripts. Inter-rater agreement for the overall interview ratings was $88 \%$. Liberal criteria were used for defining psychogenic amnesia such that the following answers were taken as evidence for this type of amnesia: denying that the most aversive war memories had been stable over the life span and/or endorsing a positive answer to the question whether the accessibility of war memories had been changed and/or indicating that there had been times that war memories were completely lost.

We used chi-square and $t$ tests to compare demographic characteristics, symptom levels, and self-reports of survivors who were in treatment and control survivors. Where appropriate, one-way analyses of variance with covariates (ANCOVA) were conducted. In addition, we calculated Pearson productmoment correlations between dissociative experiences and PTSD-related symptoms for the whole sample.

\section{RESULTS}

Both groups of survivors were comparable with respect to $\operatorname{sex}\left(\chi^{2}=1.6, d f=1, P=.2\right.$, not significant [NS] $)$ and age $(t=0.1, d f=30, \mathrm{NS})$. However, comparison survivors had more years of education than survivors who were in treatment $(t=3.2, d f=30, P<.01)$, means being 14.5 $(\mathrm{SD}=3.4)$ and $10.8(\mathrm{SD}=3.2)$ years, respectively.

Table 1 shows mean scores of both groups on PTSD symptoms and dissociation scales. Survivors who received treatment scored significantly higher on intrusion items of the Impact of Event Scale, avoidance items of the Impact of Event Scale, and the PTSD Symptom Scale. These group differences remained significant if ANCOVAs were conducted with education as covariate (all $\mathrm{F}>15.6$, all $d f=1,28$, all $P<.01$ ). The groups differed only marginally with respect to scores on the Dissociative Experiences Scale $(t=1.8, d f=29, P=.08)$ and this difference became nonsignificant when evaluated with an ANCOVA that controlled for the influence of education $(\mathrm{F}=2.6, d f=1,28, P=$ .12). However, the two groups did differ with regard to their scores on those eight items of the Dissociative Experiences Scale that, according to some authors, ${ }^{15}$ tap pathological dissociation. This group difference on so called taxon (i.e., DES-T) 
Table 1. Mean Scores on Measures of PTSD-Related Distress and Dissociation of 17 Survivors Receiving Treatment and 14 Control Survivors

\begin{tabular}{|c|c|c|c|c|c|c|}
\hline & \multicolumn{2}{|c|}{$\begin{array}{c}\text { Survivors Receiving } \\
\text { Treatment }\end{array}$} & \multicolumn{2}{|c|}{ Control Survivors } & \multicolumn{2}{|c|}{ Significance } \\
\hline & Mean & SD & Mean & SD & $t$ & $P$ \\
\hline Impact of Event Scale Intrusion & 19.1 & 10.5 & 3.8 & 6.2 & 4.8 & .001 \\
\hline Avoidance & 19.0 & 11.3 & 3.2 & 5.4 & 4.8 & .001 \\
\hline PTSD Symptom Scale & 18.9 & 9.8 & 4.5 & 5.1 & 5.0 & .001 \\
\hline Dissociative Experiences Scale & 17.3 & 10.0 & 11.7 & 5.6 & 1.8 & .076 \\
\hline Taxon items (DES-T) & 9.6 & 8.1 & 4.2 & 3.8 & 2.3 & .021 \\
\hline
\end{tabular}

NOTE. Two-tailed $t$ tests with $d f=29$.

items remained significant when the influence of education was controlled for in an ANCOVA $(\mathrm{F}=$ 4.6, $d f=1,28, P=.04)$

Pearson correlations computed for the total group of survivors showed that Dissociative Experiences Scale scores were neither related to scores on the intrusion items $(r=.21, \mathrm{~N}=31, P=.25$, NS) and avoidance items $(r=.20, \mathrm{~N}=31, P=$ $.27, \mathrm{NS})$ of the Impact of Event Scale, nor to scores on the PTSD Symptom Scale $(r=.15, \mathrm{~N}=31, P$ $=.42, \mathrm{NS})$. Much the same was true for correlations involving scores on taxon items of the Dissociative Experiences Scale. Scores on this DES-T were not related to scores on the Impact of Event subscales or those on the PTSD Symptom Scale (all $r<.21$, all $P>.16$ ). On the other hand, scores on the intrusion and avoidance items of the Impact of Event Scale were strongly linked to PTSD Symptom Scale scores (all $r>.80, \mathrm{~N}=31$, all $P<$ $.01)$.

As to interview questions addressing psychogenic amnesia, all survivors indicated that the content of their war memories had been stable over the course of their life. Twenty-four percent $(n=4)$ of the survivors who were in treatment and $14 \%(\mathrm{n}=$ 2) of comparison survivors said that the accessibility of their war memories had changed during their lives, while $53 \%(\mathrm{n}=9)$ of the treatment group and $79 \%(\mathrm{n}=11)$ of the comparison group said that memory accessibility had never changed. There were no differences between the two groups in this respect $\left(\chi^{2}=1.8, d f=3, P=.61, \mathrm{NS}\right)$. Finally, only $6 \%(\mathrm{n}=1)$ of the treatment group and $7 \%(\mathrm{n}=1)$ of the comparison group said that there had been times during which their war memories had been completely lost. In the treatment group, $35 \%(n=6)$ said that their traumatic memories had always been accessible, while $41 \%$ ( $\mathrm{n}=$ 7 ) indicated that their had been periods of reduced accessibility due to attempts to avoid these memories. Seventy-nine percent $(n=11)$ of the comparison group indicated that their war memories had always been accessible, while another $14 \%$ $(n=2)$ of them said that there had been periods that these memories had been less accessible because they had tried not to think of them. Again, there were no significant differences between the two groups with regard to this interview item $\left(\chi^{2}=4.2, d f=2, P=.12, \mathrm{NS}\right)$.

\section{DISCUSSION}

In line with the idea that dissociative symptoms are a consequence of trauma exposure, ${ }^{16}$ a number of authors ${ }^{10,17}$ have argued that PTSD symptoms are predominantly dissociative in nature. For certain types of trauma (e.g., natural disasters), there is some evidence to suggest that dissociative experiences and PTSD symptoms overlap. ${ }^{18}$ However, our results show that this overlap is not a universal phenomenon. Although survivors who were in treatment scored significantly higher on scales measuring PTSD-related distress than control survivors, the two groups did not differ in terms of self-reported dissociative symptoms. In fact, average scores on the Dissociative Experiences Scale of both survivors who received treatment and comparison survivors were well within the range that is often reported for normal populations. ${ }^{19,20}$ Eighteen percent of the survivors $(n=3)$ who were in treatment scored above the clinical cut-off point of 30 on the Dissociative Experiences Scale, ${ }^{21}$ while none of the comparison survivors scored above this cut-off point. Likewise, for the total group of survivors, correlations between scores on PTSD measures and those on the Dissociative Experiences Scale remained nonsignificant. This was even true when correlations involved mean scores on DES-T items, i.e., items that are 
thought to be sensitive to pathological forms of dissociation. Admittedly, survivors who were in treatment had higher DES-T scores than control survivors. Note, however, that recent research ${ }^{22}$ suggests that elevated DES-T scores are intimately related to personality disorders and fantasy proneness.

Taken together, our results are well in line with those of Yehuda et al., ${ }^{9}$ who concluded in their study on Holocaust survivors that PTSD symptoms and dissociative experiences are separate categories. Our failure to find a straightforward connection between dissociative experiences and PTSDrelated distress in aging concentration camp survivors may have to do with the fact that aging is often accompanied by a reduction of dissociative experiences. ${ }^{23}$ Perhaps, then, dissociative experiences and PTSD symptoms follow different trajectories in this category of traumatized individuals. Although previous work ${ }^{16}$ has drawn attention to the fact that dissociative symptoms may persist after PTSD symptoms have resided, the current findings suggest that the reversed pattern is also possible. Persistence of dissociative experiences after exposure to trauma may critically depend on the precise type of trauma and more specifically, the extent to which such trauma occurs in the context of family pathology ${ }^{24}$ Thus, it is conceivable that abuse by a trusted caretaker, but not exposure to war atrocities interferes with normal attachment patterns and in this way contributes to the overlap between dissociative experiences and PTSD symptoms. Clearly, the precise connections between dissociation, PTSD, and type of trauma warrant further study. In any case, our results as well as those of several other recent studies ${ }^{9,24-26}$ demonstrate that the link between trauma and dissociation is considerably more complicated than is often assumed.

Previous studies found relatively high rates of self-reported amnesia for childhood sexual abuse (19\% to 62\%) in patients treated for childhood abuse-related problems. ${ }^{27}$ In the current study, survivors receiving treatment and comparison survivors did not display a differential response pattern on interview items about the accessibility and stability of their war memories. Only a minority of the survivors reported mnemonic experiences that might be construed as evidence for psychogenic amnesia. In addition, such reports were not dependent on survivors being in treatment or not. Again, our results fit well with those of other studies $4,7,9$ that found psychogenic amnesia to be relatively rare among concentration camp survivors. Taken together, these findings cast doubts on the idea that amnesia is a common consequence of repetitive, prolonged, and severe trauma. ${ }^{28}$ Apparently, the relative high frequency of self-reported psychogenic amnesia found in studies relying on victims of childhood abuse ${ }^{16,17,27}$ cannot be generalized to aging concentration camp survivors. A more general issue that can be raised has to do with the fact that studies on psychogenic amnesia critically depend on self-reports about prior forgetting. As one recent experiment ${ }^{29}$ showed, such retrospective reports may also occur for nontraumatic events and there are even indications that the more people are asked to retrieve certain memories, the more these memories are judged to have been incomplete. These findings suggest that it might be problematic to pathologize reports of prior forgetting by referring to it as psychogenic amnesia.

\section{REFERENCES}

1. Karon BP, Widener JA. Repressed memories and World War II: lest we forget! Prof Psychol Res Pr 1997;28:338-340.

2. Jaffe R. Dissociative phenomena in former concentration camp inmates. Int J Psychoanal 1968;49:310-312.

3. Lilienfeld SO, Loftus B. Repressed memories and World War II: some cautionary notes. Prof Psychol Res Pr 1998;29: 471-475.

4. Kuch K, Cox BJ. Symptoms of PTSD in 124 survivors of the Holocaust. Am J Psychiatry 1992;149:337-340.

5. Wagenaar WA, Groeneweg J. The memory of concentration camp survivors. Appl Cogn Psychol 1990;4:77-87.

6. Schelach L, Nachson I. Memory of Auschwitz survivors. Appl Cogn Psychol 2001;15:119-132.

7. Maercker A, Schutzwohl M. Long-term effects of political imprisonment: a group comparison study. Soc Psychiatry Psychiatr Epidemiol 1997;32:435-442.

8. Kihlstrom JF, Schacter DL. Functional disorders of autobiographical memory. In: Baddeley AD, Wilson BA, Watts FN (eds). Handbook of Memory Disorders. New York, NY: Wiley, 1995:337-364.

9. Yehuda R, Elkins A, Binder-Brynes K, Kahana B, Southwick SM, Schmeidler J, et al. Dissociation in Holocaust survivors. Am J Psychiatry 1996;153:935-940.

10. Bremner JD, Krystal JH, Charney DS, Southwick SM. Neural mechanisms in dissociative amnesia for childhood abuse. Am J Psychiatry 1996;153(Suppl):71-82.

11. Horowitz MJ, Wilner N, Taylor KT: Impact of Event Scale: a measure of subjective distress. Psychosom Med 1979; 41:207-218. 
12. Foa EB, Riggs DS, Dancu C, Rothbaum BO. Reliability and validity of a brief instrument for assessing PTSD. J Trauma Stress 1993;6:459-473.

13. First MB, Spitzer RL, Gibbon M, Williams JBW: Structured Clinical Interview for DSM-IV Axis I Disorders 1997. New York, NY: Biometrics Research Department, 1997.

14. Bernstein EM, Putnam FW. Development, reliability, and validity of a dissociation scale. J Nerv Ment Dis 1986;174: 727-735.

15. Waller NG, Ross CA. The prevalence and biometric structure of pathological dissociation in the general population: taxometric and behavior genetic findings. J Abnorm Psychol 1997;106:499-510.

16. Van der Kolk BA, Pelcovitz D, Roth S, Mandel FS, McFarlane A, Herman JL. Dissociation, somatization, and affect dysregulation: the complexity of adaptation to trauma (festschrift). Am J Psychiatry 1996;153(Suppl):83-93.

17. Gershuny BS Thayer JF. Relations among psychological trauma, dissociative phenomena, and trauma-related distress: A review and integration. Clin Psychol Rev 1999;19:631-657.

18. Koopman C, Classen C, Spiegel D. Predictors of posttraumatic stress symptoms among survivors of the Oakland/ Berkeley, Calif, firestorms. Am J Psychiatry 1994;151:888-894.

19. Van IJzendoorn MH, Schuengel C. The measurement of dissociation in normal and clinical populations: meta-analytic validation of the Dissociative Experiences Scale. Clin Psychol Rev 1996;16:365-382.

20. Merckelbach H, Muris P, Rassin E. Fantasy proneness and cognitive failures as correlates of dissociative experiences. Pers Individ Differ 1999;26:961-967.
21. Ross CA, Joshi S, Currie R. Dissociative experiences in the general population: a factor analysis. Hosp Commun Psychiatry 1991;42:297-301.

22. Waldo TG, Merritt RD. Fantasy proneness, dissociation, and DSM-IV axis II symptomatology. J Abnorm Psychol 2000; 109:555-558.

23. Walker R, Gregory J, Oakley S, Bloch R, Gardner M. Reduction in dissociation due to aging and cognitive deficit. Compr Psychiatry 1996;37:31-36.

24. Nash MR, Hulsey TL, Sexton MC, Harralson TL, Lambert W. Long-term sequelae of childhood sexual abuse: perceived family environment, psychopathology, and dissociation. J Consult Clin Psychol 1993;61:276-283.

25. Mulder RT, Beatrais AL, Joyce PR, Fergusson DM. Relationship between dissociation, childhood sexual abuse, childhood physical abuse, and mental illness in a general population sample. Am J Psychiatry 1998;155:806-811.

26. Merckelbach H, Muris P. The causal link between selfreported trauma and dissociation: a critical review. Behav Res Ther 2001;39:245-254.

27. Chu JA, Frey LM, Ganzel BL, Ed M, Matthews JA. Memories of childhood abuse: dissociation, amnesia, and corroboration. Am J Psychiatry 1999;156:749-755.

28. Joseph R. The neurology of traumatic dissociative amnesia: commentary and literature review. Child Abuse Negl 1999;23:715-727.

29. Read DJ, Lindsay DS. "Amnesia” for summer camps and high school graduation: Memory work increases reports of prior periods of remembering less. J Trauma Stress 2000;13:129-147. 